\title{
Sexual Transmission of a Plant Pathogenic Bacterium, Candidatus Liberibacter asiaticus, between Conspecific Insect Vectors during Mating
}

\author{
Rajinder S. Mann, Kirsten Pelz-Stelinski, Sara L. Hermann, Siddharth Tiwari, Lukasz L. Stelinski*
}

Entomology and Nematology Department, Citrus Research and Education Center, University of Florida, Lake Alfred, Florida, United States of America

\begin{abstract}
Candidatus Liberibacter asiaticus is a fastidious, phloem-inhabiting, gram-negative bacterium transmitted by Asian citrus psyllid, Diaphorina citri Kuwayama (Hemiptera: Psyllidae). The bacterium is the presumed causal agent of huanglongbing (HLB), one of the most destructive and economically important diseases of citrus. We investigated whether Las is transmitted between infected and uninfected $D$. citri adults during courtship. Our results indicate that Las was sexually transmitted from Las-infected male $D$. citri to uninfected females at a low rate $(<4 \%)$ during mating. Sexual transmission was not observed following mating of infected females and uninfected males or among adult pairs of the same sex. Las was detected in genitalia of both sexes and also in eggs of infected females. A latent period of 7 days or more was required to detect the bacterium in recipient females. Rod shaped as well as spherical structures resembling Las were observed in ovaries of Las-infected females with transmission electron microscopy, but were absent in ovaries from uninfected $D$. citri females. The size of the rod shaped structures varied from 0.39 to $0.67 \mu \mathrm{m}$ in length and 0.19 to $0.39 \mu \mathrm{m}$ in width. The spherical structures measured from 0.61 to $0.80 \mu \mathrm{m}$ in diameter. This investigation provides convincing evidence that a plant pathogenic bacterium is sexually transmitted from male to female insects during courtship and established evidence that bacteria persist in reproductive organs. Moreover, these findings provide an alternative sexually horizontal mechanism for the spread of Las within populations of $D$. citri, even in the absence of infected host trees.
\end{abstract}

Citation: Mann RS, Pelz-Stelinski K, Hermann SL, Tiwari S, Stelinski LL (2011) Sexual Transmission of a Plant Pathogenic Bacterium, Candidatus Liberibacter asiaticus, between Conspecific Insect Vectors during Mating. PLoS ONE 6(12): e29197. doi:10.1371/journal.pone.0029197

Editor: François Leulier, French National Centre for Scientific Research - Université Aix-Marseille, France

Received August 31, 2011 ; Accepted November 22, 2011; Published December 21, 2011

Copyright: @ 2011 Mann et al. This is an open-access article distributed under the terms of the Creative Commons Attribution License, which permits unrestricted use, distribution, and reproduction in any medium, provided the original author and source are credited.

Funding: This research was supported by the Citrus Research and Development Foundation Inc., Florida. The funders had no role in study design, data collection and analysis, decision to publish, or preparation of the manuscript.

Competing Interests: The authors have declared that no competing interests exist.

* E-mail: stelinski@ufl.edu

\section{Introduction}

Candidatus Liberibacter asiaticus (Las) is a fastidious, phloeminhabiting, gram-negative bacterium transmitted by Asian citrus psyllid, Diaphorina citri Kuwayama (Hemiptera: Psyllidae). The bacterium is the putative causal pathogen of huanglongbing (HLB) disease of citrus; however, Koch's postulates have not yet been fulfilled [1-2]. HLB is one of the most destructive and economically important diseases of citrus worldwide [1,3]. HLB causes severe yield reduction, fruit drop, reduced fruit quality, and tree death. Gurrently, there is no cure for the disease. Two related species, Candidatus L. americanus (Lam) and Candidatus L. africanus (Laf), are also presumed casual agents of the disease [4-6]. Until recently, Lam was found only in Brazil but has now been reported in Hunan, China [6]. Laf is the presumed causal agent of HLB in South Africa, Saudi Arabia, and on a few islands in the Indian Ocean [6]. Diaphorina citri is the insect vector of Las in Asia, Brazil and U.S.A., whereas Trioza erytreae (Del Guercio) (Triozidae) is the vector of Laf $[1,6,7]$.

Las is acquired more efficiently by psyllid nymphs than adults $[8,9,10]$. Although up to $100 \%$ of $D$. citri reared on infected citrus may acquire Las, acquisition by adults averaged $40 \%$ following 5 weeks of feeding on infected plants [10]. Furthermore, successful transmission, as measured by plant infection, by individual $D$. citri may range from 4 to $10 \%$ annually, following inoculations [10]. Certain studies have suggested that Las persists and replicates within the vector following acquisition $[8,9]$. In addition to acquisition from infected host plants, Las is transmitted transovarially at a low rate $(2-6 \%)$ from infected females to their offspring [10]. To date, sexual transmission of plant pathogenic bacteria among mating pairs of insects has not been investigated.

Several arthropod viruses and protozoa are sexually transmitted between partners, (reviewed by Knell and Webberley, [11]). Insect-transmitted animal and plant viruses such as the Dengue Fever virus, St. Louis Encephalitis virus, Tomato yellow leaf curl virus, Squash leaf curl virus, and Watermelon chlorotic stunt virus are transmitted during mating [11-13]. Sexual transmission of these viruses is presumably an adaptation that enables horizontal spread within the vector population and may be an important factor in maintaining these viruses in their vector populations if plant hosts are absent or vertical transmission is inefficient [14-15].

Although many insect bacteria are known to be vertically transmitted from mother to offspring, sexual transmission of bacteria between partners has rarely been reported in insects $[11,16]$. Sexual transmission of the endosymbiotic bacteria, Candidatus Hamiltonella defensa and Candidatus Regiella insecticola, was recently described in the pea aphid, Acyrthosiphon pisum 
[17]. Similarly, sexual transmission of symbiotic bacteria belonging to the genus Asaia was demonstrated in Anopheles stephensi mosquitoes [16]. Wolbachia spp. have been recorded in the testes and ovaries of male and female insects, which suggested the possibility of sexual transmission; however, these are exclusively vertically transmitted via egg cytoplasm and are not transmitted to females during mating [18]. The absence of bacterial transmission from males to females in Drosophila melanogaster during mating is attributed to the production of a peptide with anti-microbial properties, termed "andropin". Andropin is presumed to be manufactured in the testes of male $D$. melanogaster and passed to females during mating to prevent sperm degradation $[11,19,20]$. The protein is secreted into female accessory fluid during copulation [11]. However, Otti et al. [21] did not find andropin in male ejaculates of the bed bug, Cimex lectularius, but suggested male sperm protection through production of bacteriolytic lysozymes. Although sexual transmission of endosymbiotic bacteria is known to occur as described above, sexual transmission of insect-transmitted plant pathogenic bacteria has not been reported previously. Herein, we report sexual transmission of Las from infected male $D$. citri to females during mating.

\section{Materials and Methods}

\section{Maintenance of insects, pathogen and host plants}

Uninfected adult $D$. citri used in bioassays were obtained from a laboratory culture continuously reared at the University of Florida Citrus Research and Education Center (Lake Alfred, USA). The culture was established in 2000 from field populations in Polk Co, FL, U.S.A. $\left(28.0^{\prime} \mathrm{N}, 81.9^{\prime} \mathrm{W}\right)$ prior to the discovery of HLB in the State. Insects were maintained on sour orange (Citrus aurantium L.) and 'Hamlin' orange [C. sinensis (L.) Osb.] at $27 \pm 1{ }^{\circ} \mathrm{C}, 63 \pm 2 \%$ $\mathrm{RH}$, and a 14:10 L:D photoperiod. Monthly testing of randomly sampled D. citri nymphs and adults was conducted using quantitative real-time polymerase chain reaction (qPCR, described below) to confirm that psyllids did not harbor Las. Diaphorina citri harboring Las were obtained from Las-infected C. aurantium and $C$. sinensis plants maintained in a secure quarantine facility under the same environmental conditions used for rearing the uninfected D. citri culture. The Las-infected culture originated from the uninfected culture. Routine sampling indicated that approximately $40 \%$ of $D$. citri individuals obtained from the infected culture were positive for Las when groups of 10-20 psyllids were tested with qPCR. Uninfected and Las-infected D. citri cultures were maintained in separate rearing facilities to preclude cross contamination.

Cultures of Las in plants were maintained by graft-inoculating healthy $C$. sinensis with Las-infected budwood collected from commercial citrus groves in Immokalee, FL (Collier Co.). Bergera koenigii plants were obtained as potted seedlings from an HLB-free local nursery. The plants were confirmed negative for Las infection with qPCR. Uninfected and Las-infected plants were maintained in separate, secure greenhouses to minimize the likelihood of cross contamination.

\section{Detection of Las in insect and plant samples using qPCR}

Dual-labeled probes were used to detect Las in D. citri and plants using an ABI 7500 qPCR system (Applied Biosystems, Foster City, CA) in a multiplex TaqMan qPCR assay previously described by Li et al. [22] and Pelz-Stelinski et al. [10]. DNA from insect and plant samples was isolated using the DNeasy blood and tissue or DNeasy plant kits (Qiagen Inc, Valencia, CA), respectively. The target primers LasF (5'-TGGAGGGCGTATGCAATACG-3'), LasR (5'-GGGTTATCGCGTAGAAAAAGG-
TAG-3') and the probe HLBp (FAM-AGACGGGTGAGTAACGCG-BHQ1) were used for amplifications of Las-specific 16S rDNA from psyllid and plant extracts. Reactions were conducted using probe-primer sets targeting internal control sequences specific to D. citri [insect wingless: WgF (5'-GCTCTCAAAGATCGGTTTGACGG-3'), WgR (5'-GCTGCGACGAACGTTACCTTC-3), WGp (FAM- TTACTGACGATCACTCTGGACGC - BHQ2)] or plant [cytochrome oxidase: CoxF (5'-GTATGCGACGTCGCATTCGAGA-3'), CoxR (5'-GCGAAAACTGCTAAGGGCATTC-3'), and COXp (FAM- ATCCAGATGGTTAGGCTGG -BHQ2)] gene regions [10,22,23]. All primers and probes were obtained from Integrated DNA Technologies (Coralville, IA). Psyllid PGR reactions contained $1 \mu \mathrm{l}$ of DNA template, $12.5 \mu \mathrm{l}$ of TaqMan Universal PCR Master Mix (Applied Biosystems), $235 \mathrm{nM}$ of each of target primer, and $118 \mathrm{nM}$ each of $\mathrm{Wg}$ and Las probes. Plant reactions were conducted similarly, with $216 \mathrm{nM}$ of Las primers, $270 \mathrm{nM}$ internal control primers, and $135 \mathrm{nM}$ of each probe. Duplicate PCR reactions for each sample were performed in 96-well MicroAmp reaction plates (Applied Biosystems, Carlsbad, CA,) using an initial denaturation step of $95^{\circ} \mathrm{C}$ for $10 \mathrm{~min}$, followed by 40 cycles of $95^{\circ} \mathrm{C}$ for $15 \mathrm{~s}$ and $60^{\circ} \mathrm{C}$ for $60 \mathrm{~s}$. In addition to samples, each plate also contained a no template (negative) control, a positive control for Las, and a positive control for psyllid or plant DNA. Reactions were considered positive for either target sequence if the cycle quantification $(\mathrm{Cq})$ value, determined by the ABI 7500 Real-Time software (version 1.4, Applied Biosystems), was $\leq 36$.

\section{Sexual transmission assays}

To determine whether Las is transmitted sexually between $D$. citri during mating, the following treatments were established: 1) infected (Las+) male and uninfected (Las -) female; 2) Las+ female and Las - male; 3) Las+ female and Las - female; 4) Las+ male and Las - male; 5) Las - female and Las - male (negative control) and; 6) Las+ female and Last male (positive control). For each treatment, psyllids were enclosed in plastic Petri dishes $(60 \mathrm{~mm}$ diam) (Fisherbrand, Thermo Fisher Scientific, Waltham, MA) containing $1.5 \%$ agar to form a solidified bed. Each solidified agar bed was covered with Whatman no. 1 filter paper (Whatman Inc, Piscataway, NJ) to prevent insects from sticking to the agar. Psyllids were provided with $10 \%$ sugar solution enclosed within two stretched Parafilm strips. The sucrose-solution artificial diet was employed to preclude transmission of the Las pathogen between psyllids due to feeding. For each treatment combination, four pairs of sexually mature $(>3$ days old, Wenninger and Hall [24]) adult psyllids were enclosed in Petri dishes and held at $25 \pm 1{ }^{\circ} \mathrm{C}, 50 \pm 5 \% \mathrm{RH}$ and a 14:10 (L:D) photoperiod for a $72 \mathrm{~h}$ mating period. In treatments with same sex couples, infected or uninfected psyllids were marked with a florescent dot on the thorax to identify the potential donor of Las. This marking procedure was rotated and randomized between infected and uninfected psyllids. After $72 \mathrm{hr}$, psyllids were collected and stored in $80 \%$ ethanol at $-20^{\circ} \mathrm{C}$ for subsequent DNA extraction and Las detection with qPCR, as described above. Each treatment combination was replicated 20 times comprising four donor and four recipient insects per replication. The entire experiment was repeated twice on different dates resulting in 160 donors (initially positive) and 160 recipient (initially negative) insects for each treatment combination.

A second experiment was conducted that evaluated the same treatment combinations described above. However, the objective was to include a latent period following mating to allow more time for potential bacterial replication. Psyllid pairs were confined in agar-filled Petri dishes for $72 \mathrm{hr}$ to allow mating as described 
above. Thereafter, psyllids were segregated and recipient insects were reared for an additional 7 or 14 days to allow time for potential multiplication of sexually transmitted Las. During this latent period, psyllids were enclosed within mesh sleeve cages on $B$. koenigii plants, which are hosts for $D$. citri but not Las [25]. All $B$. koenigii test plants were analyzed for Las infection four months after experiments were conducted to ensure that they had not become infected with Las. Donor and recipient psyllids were then stored in $80 \%$ ethanol at $-20^{\circ} \mathrm{C}$ prior to qPCR detection of Las. The entire experiment was replicated twice on different dates, with each treatment combination replicated 20 times $(n=160$ per combination).

\section{Detection of Las in D. citri genitalia}

The objective of this experiment was to determine if Las was present in testis or ovaries of male or female Las-infected D. citri, respectively. Male and female $D$. citri adults reared on Las-infected citrus plants were anesthetized by freezing at $-20^{\circ} \mathrm{C}$ for $\approx 5 \mathrm{~min}$. Anesthetized adults were dissected in $1 \times$ PBS $10 \mathrm{mM}$ phosphate buffer saline (PBS, pH 7.4) using a steel surgical dissecting knife (Fisher Scientific, Waltham, MA) under a Wild MC3 stereomicroscope (Leica, Heerbrugg, Switzerland). Las infection in dissected adults was subsequently confirmed with qPCR. Genitalia were extracted and successively washed with $70 \%$ ethanol, $10 \%$ sodium hypochlorite (Clorox ${ }^{\circledR}$, regular bleach), and sterile $1 \times$ PBS to remove hemolymph-derived Las contamination prior to storage in $80 \%$ ethanol at $-20^{\circ} \mathrm{C}$. Ovaries and testis obtained from adults that tested positive were further analyzed by qPCR for Las infection in groups of one or five specimens. For males, the testis and adeagus were analyzed simultaneously because of their small size and to avoid loss of bacteria during dissection. In total, 34 male and 32 female individual genital samples obtained from confirmed Las-positive $D$. citri adults were analyzed for each sex. Twenty specimens for each sex were analyzed when the genitalia were tested in groups of five. An equal number of genital samples obtained from confirmed Las-negative $D$. citri adults were used as a negative control.

\section{Detection of sexually-transmitted Las in unlaid eggs of $D$. citri females which acquired Las during mating}

The objective of this experiment was to determine if Las was present in unlaid eggs of female $D$. citri, which acquired the bacterium from males during mating. In this experiment, uninfected females were mated with presumably Las-positive males in Petri dishes to obtain Las-positive females using the above-described procedures. Uninfected females mated with uninfected males were used as a negative control. Las-positive females mated with Laspositive males were used as a positive control. Each treatment combination was replicated 80 times comprising four donor and four recipient insects per replication. After 3 days, females that presumably acquired Las sexually were removed from the Petri dishes and released onto B. koenigii plants housed within mesh sleeve cages. Seven days later, female $D$. citri were collected and dissected in $1 \times$ PBS to extract ovaries and unlaid eggs. Eggs were successively washed with $70 \%$ ethanol, $10 \%$ sodium hypochlorite, and sterile $1 \times$ PBS to remove hemolymph-derived Las contamination. This procedure was verified in preliminary testing to remove potential Las contamination and our negative and positive control treatments (see Results) corroborate that contamination did not occur. Extracted egg samples were stored in $80 \%$ ethanol at $-20^{\circ} \mathrm{C}$ for subsequent qPCR analysis. Las infection in dissected adults (from which eggs were extracted) was confirmed with qPCR as described above. Unlaid eggs $(n=180)$ obtained from females that acquired bacteria from males $(n=9)$ were further analyzed for Las infection.
Eggs were analyzed for Las infection in groups of 20 specimens resulting in 9 egg samples. Egg samples for the negative control and positive control treatments comprised 20 samples in groups of 20 specimens.

\section{Detection of sexually-transmitted Las in F1 offspring of females that acquired Las during mating}

To determine if females that acquired Las during mating could subsequently transmit the bacterium transovarially, sets of four sexually mature, Las-negative female $D$. citri were confined with Las-positive males in Petri dishes to allow mating. Uninfected females confined with uninfected males were used as a negative control. In total, there were 40 Petri dishes for each treatment with each Petri dish representing a replicate. After 3 days, females were removed from Petri dishes and released onto B. koenigii plants for 7 days to allow egg laying in batches of 20 insects per plant resulting in eight replicates for each treatment. The eggs were allowed to develop and emerging adults (F1) were analyzed for Las infection using qPCR. The parent male and female psyllids were stored in $80 \%$ ethanol at $-20^{\circ} \mathrm{C}$ and also analyzed for Las infection with qPCR. All B. koenigii plants were analyzed for Las infection four months after the experiment was conducted to ensure they had not become infected with Las.

\section{Transmission Electron Microscopy (TEM) of ovaries from Las-infected females}

Ovaries of Las-infected $D$. citri were inspected by TEM to determine whether they harbored structures that resemble Las morphologically. Twenty D. citri females, presumably infected with Las, were examined. These psyllids were obtained from the Lasinfected culture described previously. As a negative control, twenty uninfected females reared on healthy citrus plants were also examined. Insects were anesthetized by freezing at $-20^{\circ} \mathrm{C}$ for $\approx 5 \mathrm{~min}$, then decapitated using a steel surgical dissecting knife. Ovaries were removed from females under $40 \times$ magnification using a Wild MC3 dissecting microscope, then subjected to disinfecting and washing as described above. Samples were prepared for TEM as in Onagbola et al. [26]. Briefly, individual ovaries were fixed in $3 \%$ glutaraldehyde in $0.1 \mathrm{M}$ potassium phosphate buffer $\left(\mathrm{pH} \mathrm{7.2)}\right.$ for $24 \mathrm{~h}$ at $4^{\circ} \mathrm{C}$. After rinsing in the buffer solution, samples were post fixed in $1 \%$ osmium tetroxide for $2 \mathrm{~h}$, washed in $2 \times$ phosphate buffer, then fixed in $2 \%$ osmium tetroxide for $6 \mathrm{~h}$ at room temperature. The tissues were dehydrated in $10,20,30,100 \%$ acetone for $0.25,0.25,0.25$, and $3 \mathrm{~h}$, respectively, and then infiltrated in 30, 50, 70, and 100\% Spurr's resin for 1, 8, 14, and $14 \mathrm{~h}$, respectively. Samples were embedded in pure Spurr's plastic for $24 \mathrm{~h}$, placed in molds, covered with fresh resin, and oven dried at $70^{\circ} \mathrm{C}$ for $24 \mathrm{hr}$. Polymerization was performed at $70^{\circ} \mathrm{C}$ for $72 \mathrm{hr}$. Ultrathin sections of the tissues were cut with a diamond knife on an ultramicrotome (model 8365, LKB-Huxley Cambridge, United Kingdom) and placed on Gilder grids previously coated with $0.5 \%$ formvar (Electron Microscopy Sciences, Fort Washington, PA) solution. Blocks were sectioned, stabilized in $2 \%$ uranyl acetate, and placed on $0.5 \%$ formvar-coated nickel grids (Electron Microscopy Sciences, Fort Washington, PA, 200 mesh) and stained with uranyl-acetate ( $2 \%$ aqueous, $20 \mathrm{~min}$ ) and lead citrate (6 min). Grids with the affixed ultrathin sections were cleared by submersing in lead citrate to regulate electron density. Sections were rinsed with $2 \%$ sodium hydroxide solution followed by excess distilled water before examination under a Morgagni \#268 transmission electron microscope (FEI Electron Optics, Einhoven, The Netherlands) at $60 \mathrm{kV}$. 


\section{Transmission of Las to healthy plants following sexual transmission}

An experiment was conducted to test whether female $D$. citri that obtained Las through sexual transmission from infected males would subsequently transmit the bacterial pathogen to uninfected citrus plants by feeding. Las-negative female $D$. citri were confined with Las-positive males in Petri dishes to allow mating as described above. Uninfected females confined with uninfected males were used as a negative control. After 3 days, females were removed from Petri dishes and released onto 2-3 month-old, uninfected (confirmed by qPCR) grapefruit plants (Citrus paradesi) and allowed to feed for a 7-day inoculation access period (IAP). In total, each treatment was replicated 10 times (10 plants) and 10 female $D$. citri were released per replicate plant following mating. The entire experiment was replicated twice. Following 7 day IAP, all living $D$. citri were collected, freeze killed and placed individually into sterile $1.5 \mathrm{~mL}$ centrifuge tubes containing $80 \%$ ethanol and stored at $-20^{\circ} \mathrm{C}$ until DNA extraction. All plants were maintained in Plexiglass cages for eight months as described above for plant maintenance. Plants were sampled (as described above) for Las infection at 4 and 8-month intervals following IAP to determine infection status. Male and female $D$. citri were also tested for Las infection directly following mating and IAP, respectively, using the qPCR methods described above.

\section{Data Analysis}

Logistic regression with Firth's bias reduction was used to analyze the data from all experiments. The data from the sexual transmission assays were analyzed using mating pair treatment and post-mating latent period as independent variables and infection status of the recipient insect as the dependent variable (PROG LOGISTIC, SAS Institute, Cary, NG). Duration of postmating period did not significantly impact the infection status of recipient insects. Therefore, data from post mating periods were pooled for further analysis. Data from experiments evaluating Las in genitalia were also analyzed using logistic regression with Firth's bias reduction using source of genitalia, gender, and grouping as independent variables and infection status of genitalia as a dependent variable. In experiments evaluating transovarial transmission, mating pairs were used as an independent variable, while infection status of eggs or F1 offspring was used as a dependent variable.

\section{Results}

\section{Sexual transmission assays}

In the first experiment, an infection rate of $44 \%$ was observed in donor Las-infected male or female $D$. citri paired with uninfected male or female partners. For all mating pair treatments, Las was not detected in recipient male or female $D$. citri collected immediately after the $72 \mathrm{~h}$ mating period.

In contrast, mating pair treatment type significantly affected infection status of recipient insects when the same mating pairs were provided with a post-mating period $\left(\chi^{2}=98.81, \mathrm{df}=5\right.$, $\mathrm{p}<0.01$ ). When infected males (donor insect) were mated with uninfected females (recipient insect), 3.8\% of the recipient females acquired Las from donor males (Table 1). Las was not detected in recipient male or female insects which were confined with donor insects of the same sex. Las was also not detected in B. koenigii plants four months after experiments were conducted.

\section{Detection of Las in D. citri genitalia}

Source of genitalia significantly affected the presence of Las in D. citri genitalia $\left(\chi^{2}=6.03, \mathrm{df}=1, \mathrm{p}=0.01\right)$. Las was detected in $13.5 \%$ of genital samples when genitalia were extracted from Laspositive pyllids (Table 2). No Las was detected in the genetalia of psyllids from the uninfected culture (Table 2). The odds (ratios of probabilities) that genitalia were positive for Las was 31.4 times greater when samples were extracted from Las-positive than negative psyllids. Las was detected in $5.9 \%$ of male and $12.5 \%$ of female genital samples from individual Las-infected $D$. citri (Table 2). The odds of Las infection was 2.4 times greater for female than male genitalia. However, Las infection was statistically equivalent in the genitalia of males and females. When the genitalia from Las-infected psyllids were pooled in groups of five insects, $10.0 \%$ of male and $25.0 \%$ of female genital samples tested positive for Las (Table 2). The odds of detecting Las from pooled genital samples were 2.1 times greater than from individual samples. However, there was no significant effect of pooling samples on Las infection in D. citri genitalia.

\section{Detection of sexually-transmitted Las in unlaid eggs of $D$.} citri females that acquired Las during mating

In this experiment, $2.8 \%$ of the initially uninfected females acquired Las from infected males during mating (Table 3). All

Table 1. Venereal transmission of Las between adult $D$. citri.

\begin{tabular}{|c|c|c|c|}
\hline Mating pair treatment & $\begin{array}{l}\text { Percent of donor } \\
\text { insects that were } \\
\text { infected with Las }\end{array}$ & $\begin{array}{l}\text { Percent of recipient insects } \\
\text { that became infected with } \\
\text { Las after mating }\end{array}$ & $\begin{array}{l}{ }^{3} \text { Odds ratios of recipient } \\
\text { insect acquiring Las } \\
\text { over negative control }\end{array}$ \\
\hline Las-positive males mated with Las-negative females & $43.8^{1}(0.04)^{2}$ & $3.8(0.01)$ & 13.5 \\
\hline Las-negative males mated with Las-positive females & $42.5(0.04)$ & $0.0(0.00)$ & 1 \\
\hline Las-negative females mated with Las-positive females & $38.8(0.04)$ & $0.0(0.00)$ & 1 \\
\hline Las-negative males mated with Las-positive males & $37.5(0.03)$ & $0.0(0.00)$ & 1 \\
\hline $\begin{array}{l}\text { Las-negative males mated with Las-negative } \\
\text { females (negative control) }\end{array}$ & $0.0(0.00)$ & $0.0(0.00)$ & 1 \\
\hline $\begin{array}{l}\text { Las-positive males mated with Las-positive } \\
\text { females (positive control) }\end{array}$ & $40.6(0.04)$ & $45.0(0.04)$ & 262.9 \\
\hline \multicolumn{4}{|c|}{$\begin{array}{l}{ }^{1} \text { Samples were considered positive if the Cq values were } \leq 36 . \\
{ }^{2} \text { Values in parenthesis are standard error of means. } \\
{ }^{3} \text { Odds (ratios of probabilities) of detecting Las in a particular mating pair treatment over the odds of detecting Las in the negative control. An odds ratio }=1.0 \text { indicates } \\
\text { equal chance of detecting Las between treatment and control. } \\
\text { doi:10.1371/journal.pone.0029197.t001 }\end{array}$} \\
\hline
\end{tabular}


Table 2. Infection status of $D$. citri genitalia from Las-positive and negative cultures.

\begin{tabular}{|c|c|c|c|c|}
\hline \multirow[b]{2}{*}{ Source of $D$. citri genitalia ${ }^{1}$} & \multirow[b]{2}{*}{ D. citri gender } & \multicolumn{3}{|c|}{ Percent of $D$. citri genital samples that were infected with Las } \\
\hline & & $\begin{array}{l}\text { Individual } \\
\text { genital samples }\end{array}$ & $\begin{array}{l}\text { Pooled from five } \\
\text { genital samples }\end{array}$ & $\begin{array}{l}\text { Combined } \\
\text { mean }^{4}\end{array}$ \\
\hline \multirow[t]{2}{*}{ Confirmed Las-positive insects } & Male & $5.9^{2}(0.04)^{3}$ & $10.0(0.07)$ & \\
\hline & Female & $12.5(0.03)$ & $25.0(0.10)$ & $13.48 \mathrm{a}$ \\
\hline \multirow[t]{2}{*}{ Confirmed Las-negative insects } & Male & $0.0(0.00)$ & $0.0(0.00)$ & \\
\hline & Female & $0.0(0.00)$ & $0.0(0.00)$ & $0.0 \mathrm{~b}$ \\
\hline Mean & - & 9.2 & 17.5 & - \\
\hline
\end{tabular}

${ }^{1}$ Genitalia were secured from confirmed Las-positive or Las-negative $D$. citri.

${ }^{2}$ Samples were considered positive if the Cq values were $\leq 36$.

${ }^{3}$ Values in parenthesis are standard error of means.

${ }^{4}$ Combined mean percent of Las infection in male and female $D$. citri derived from combined individual and pooled samples.

Values within columns labeled with different letters are significantly different $(p<0.05)$.

doi:10.1371/journal.pone.0029197.t002

unlaid egg samples from females that acquired Las from infected males were negative (Table 3). There were no significant differences between the treatments tested for Las infection; however, $5.0 \%$ of unlaid egg samples obtained following matings of Las-positive males with Las-positive females (positive control) were positive for Las (Table 3). For the negative control, Las was not detected in eggs of donor or recipient insects (Table 3).

\section{Detection of sexually-transmitted Las in F1 offspring of females that acquired Las during mating}

In this experiment, $5.6 \%$ of the initially uninfected parent females acquired Las from infected males during mating. None of the uninfected female $D$. citri confined with uninfected males (negative control) tested positive for Las. There was no significant difference between the number of $\mathrm{F} 1$ adults emerging from matings of Las-positive males with Las-negative females and those emerging from Las-negative females mated with Las-negative males. Las was detected in $0.8 \%$ of $\mathrm{F} 1$ adults emerging from eggs that resulted from matings between Las-positive males with Lasnegative females. No Las was detected in F1 adults emerging from the negative control treatment.

\section{Transmission Electron Microscopy (TEM) of ovaries from Las-infected females}

Rod-shaped as well as spherical structures resembling Las were observed under TEM in the ovaries extracted from females that tested positive for Las with qPCR (Figure 1 A,B). Rod-shaped structures varied in size from 0.39 to $0.67 \mu \mathrm{m}$ in length and 0.19 to $0.39 \mu \mathrm{m}$ in width (Figure $1 \mathrm{~A}$ ). The spherical structures measured 0.61 to $0.80 \mu \mathrm{m}$ in diameter (Figure $1 \mathrm{~B}$ ). Ovaries from female psyllids that were confirmed negative for Las by qPCR were devoid of structures similar to those observed from positive females following an identical microscopic evaluation.

\section{Transmission of Las to healthy plants following sexual transmission}

At 4 and 8 months following a 7-day IAP by initially uninfected female $D$. citri that were mated with presumably infected male $D$. citri, none of the initially healthy citrus plants (Citrus paradesi) tested were positive for Las. Approximately $43 \%$ of donor males were infected with Las in this experiment and $2.3 \%$ of recipient females were infected with Las post mating.

\section{Discussion}

Detection of Las in female psyllids reared on Las-free citrus plants after mating with infected males strongly suggests that this plant pathogenic bacterium was transferred sexually from male to female insects during mating. This was also confirmed with lack of transmission from females to males, or between same sex pairs. While this phenomenon has been demonstrated experimentally for endosymbiotic bacteria of insects, this is the first report of sexual transmission of plant pathogenic bacteria among insect vectors.

Las presumably persists and multiplies within $D$. citri following acquisition $[9,27]$. This may explain why Las was not detected in recipient females immediately after mating with infected males, but instead required a seven-day or longer latent period prior to detection. It is possible that only a small number of bacteria are passed from males to females during mating, which must then replicate within the psyllid before reaching a sufficient titer for

Table 3. Infection status of unlaid eggs from $D$. citri females that acquired Las during mating.

\begin{tabular}{llll}
\hline & & Percent Las infection following mating \\
\cline { 2 - 3 } Mating pair treatment & Entire recipient female insects analyzed & Unlaid eggs only from recipient females \\
\hline Las-positive males mated with Las-negative females & $2.8^{1}(0.01)^{2}$ & $0.0(0.00)$ \\
Las-positive males mated with Las-positive females & $44.7(0.03)$ & $5.0(0.05)$ \\
Las-negative males mated with Las-negative females & $0.0(0.00)$ & $0.0(0.00)$ \\
\hline $\begin{array}{l}{ }^{1} \text { Samples were considered positive if the Cq values were } \leq 36 . \\
\text { 2Values in parenthesis are standard error of means. } \\
\text { doi:10.1371/journal.pone.0029197.t003 }\end{array}$ & &
\end{tabular}



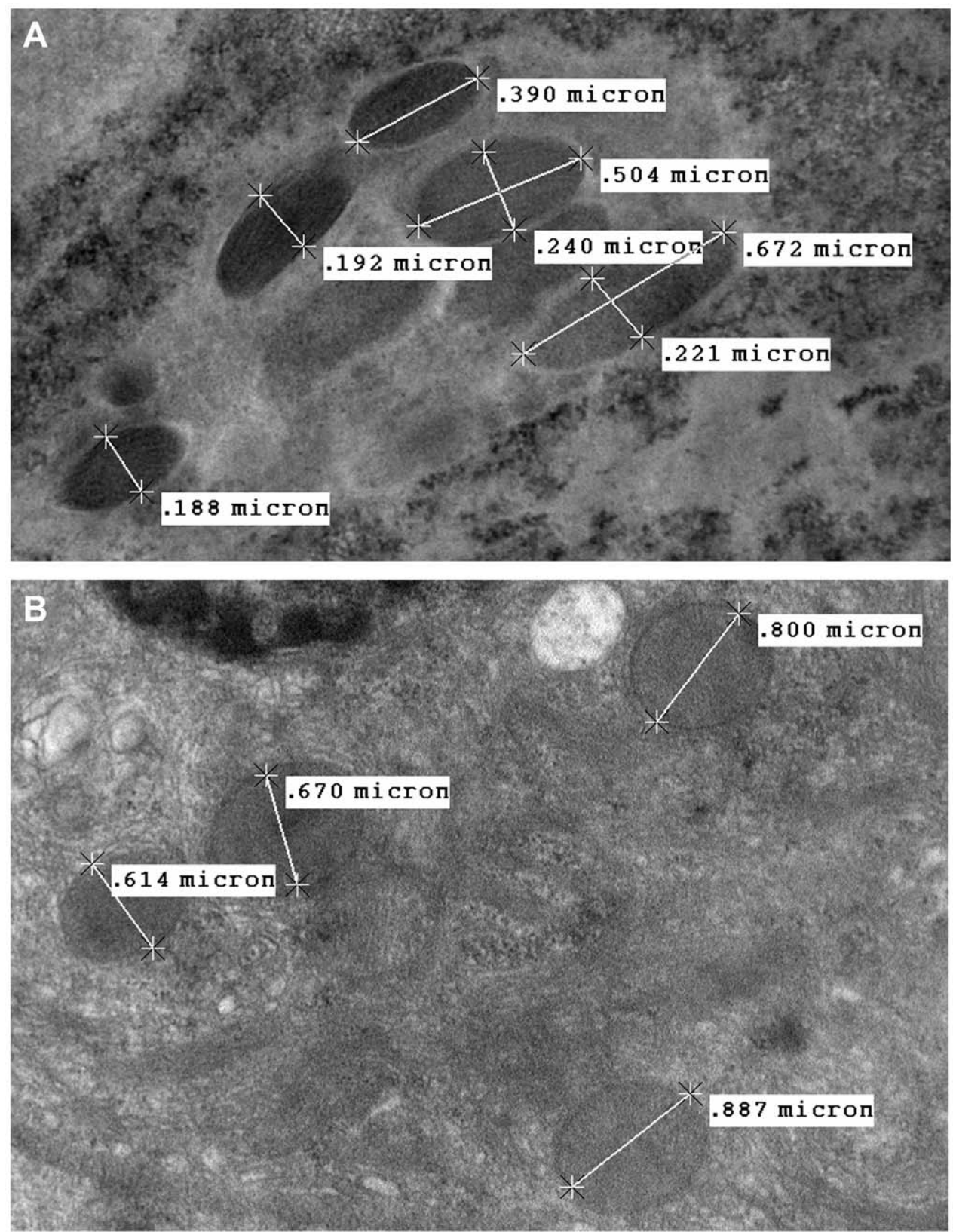

Figure 1. Rod shaped (A) and spherical (B) structures resembling Las in ovaries of Las-infected female $D$. citri observed with transmission electron microscopy. Ovaries from female psyllids that were confirmed negative for Las by qPCR were devoid of structures similar to those observed from positive females following an identical microscopic evaluation.

doi:10.1371/journal.pone.0029197.g001

detection by qPCR. These results are congruent with those of Pelz-Stelinski et al. [10], who reported a one-week latent period prior to detection of Las by identical qPCR methods following feeding on Las-infected plants.

The distribution of Las appears to be ubiquitous throughout the hemolymph and organs of infected psyllids, although the bacterial titer is highest in the alimentary canal and salivary glands [28]. We observed a low bacterial titer ( $\mathrm{Cq}$ values 37 to 39 ) in $2.3 \%$ and $8.9 \%$ of individual male and female genital samples, respectively (data not shown), suggesting a low bacterial titer in the reproductive organs of $D$. citri. Cq values could also be high because of the small amount of tissue that is processed during DNA extraction even though there may be a high bacterial load relative to the size of the organ examined. If the overall titer of bacteria in the infected psyllid donor is low, the likelihood of bacteria occurring in the reproductive organs should also be correspondingly low.

In the current investigation, the rate of Las transmission from infected males to uninfected females was low $(3.8 \%)$. In addition to low bacterial titer, several other factors could contribute to the low rate of Las transmission to females, including the timing of mating relative to oviposition, insect age, interactions between the pathogen and other psyllid symbionts, or physiological responses of psyllids to the pathogen [11]. In particular, the presence of antibacterial peptides may reduce Las titer in the sperm of infected male psyllids. Antibacterial peptides, which occur in sperm of 
certain insect species, function to protect sperm from degradation by pathogenic bacteria $[11,20,21]$. However, reports of sperm protection are limited to andropin in D. melanogaster and bacteriolytic lysozymes in Cimex lectularius and have not been documented in other insect species. Furthermore, antibacterial peptide production is a specific response induced by contact with pathogenic bacteria [29]. If similar peptides were identified in association with male psyllids, it is unclear whether Las would be recognized as pathogenic.

Presence of bacteria in male genitalia implicates their transfer through sperm and/or other seminal fluids during mating as the mechanism of venereal transmission. During copulation, male insects transfer sperm to females, as well as, a variety of other substances including seminal proteins and peptides produced in accessory glands [30]. The components and quantity of ejaculate or seminal fluids transferred from male to female $D$. citri have not been investigated to date. Traumatic insemination or wounding is also possible during mating; however, it is an unlikely mechanism by which Las may be transmitted from males to females. Such mating behavior has not been documented for D. citri and female to male or same sex transmissions were not observed.

Both rod shaped $(0.4$ to $0.7 \mu \mathrm{m}$ in length and 0.2 to $0.4 \mu \mathrm{m}$ in width) and spherical (0.61 to $0.80 \mu \mathrm{m}$ in diameter) structures were observed in ovaries of females that were infected by Las (Figure 1 A,B). These structures were morphologically similar in size and appearance to previously reported rod shaped ( 0.6 to $1.2 \mu \mathrm{m}$ in length and 0.2 to $0.8 \mu \mathrm{m}$ in width) and spherical ( 0.1 to $0.2 \mu \mathrm{m}$ in diameter) structures identified as Las in citrus plant tissues [3135]. However, the identity of these structures requires confirmation by molecular assays. Fluorescent in situ hybridization (FISH) would be an optimal technique to further confirm the identity of bacteria associated with female $D$. citri ovaries; however, this is currently not possible given that Las remains recalcitrant to culturing [34]. Until this occurs, non-specific probes targeting bacterial $16 \mathrm{~S}$ rRNA coupled to immunogold or fluorescent labels remain the only options for targeting Las in psyllids. Although FISH would confirm the presence of bacterial cells, this technique would not provide further taxonomic clarification of the identity of bacteria as compared with TEM.

Detection of Las in the unlaid eggs and offspring of infected females is congruent with previously reported transovarial transmission of Las by D. citri [10]. Las was not detected in egg samples collected from recipient females that acquired Las from infected males. The small sample size available for testing likely contributed to the lack of positive egg samples from this treatment. Transovarial transmission of Las by $D$. citri is reported to occur at a rate of $3.6 \%$. The current results indicate that less than $6 \%$ of females acquired the bacteria sexually; hence, only a small percentage of these females could be expected to transmit Las transovarially. In addition, it was necessary to pool eggs from infected females for analysis, as the titer of DNA present in individual eggs is insufficient for qPCR analysis [27]. Pooling eggs for pathogen detection may have diluted bacterial titer from Laspositive eggs within the samples tested, resulting in a bacterial titer below detectable limits. Detection of Las in F1 offspring of females that acquired Las during mating further confirmed that venereally acquired Las is subsequently transmitted transovarially.

Sexual transmission of endosymbiotic bacteria between insects during mating has been reported previously $[11,16,17]$. The relationship between Candidatis Liberibacter spp. and psyllid vectors is presumed to be symbiotic, with Las acting both as a phloem limited plant pathogen and as an insect symbiont [36-39]. It remains unclear whether the pathogen evolved within the psyllid vector or its host plants; however, recent studies examining the fitness of infected psyllids suggest that the pathogen-vector relationship is a welladapted mutualism [Pelz-Stelinski et al. unpublished results]. Sexual transmission of Las provides additional, albeit indirect, evidence that the relationship between the pathogen and $D$. citri could be mutualistic rather than pathogenic. However, the potential benefits D. citri receives from Las infection require further investigation.

Sexual transmission of Las may confer similar benefits to those associated with transovarial transmission. The success of plant pathogen propagation should be higher if horizontal and vertical mechanisms of transmission exist within populations of insect vectors, particularly during periods when host plant species are absent or in limited supply. This may be particularly true for Las, for which $D$. citri is the only known vector [1]. D. citri can survive and, in some cases, reproduce on a range of Rutaceous host plant species that vary in their susceptibility to Las infection $[1,25,40,41]$. Transfer of Las during mating and through transovarial transmission ensures that populations of Las survive until a favorable plant host becomes available. Sexual transmission of plant pathogens may be a particularly beneficial adaptation for maintaining their populations within insect vector populations when vertical transmission is low or completely absent [14-15]. Inoculation of plants by females that acquired Las sexually was not observed in the current study. Given that the probability of Las inoculation into a citrus plant by a single psyllid is 0.062 [10] and the probability of sexual transmission between infected males and uninfected females is 0.038 [current results], the combined probability of successful inoculation of a plant by a single female $D$. citri that acquired Las sexually would be $2 \times 10^{-3}$. Therefore, approximately 500 uninfected female psyllids would need to be mated with known Las-infected males to result in inoculation of a single host plant as per the methods used in the current investigations. Assuming an average male infection rate of $40 \%$, 1,250 individual mating experiments between pairs of male and female psyllids would be required to obtain a single infected plant. Given the number of sexual transmissions we were logistically capable of conducting, this likely explains why we were unable to document subsequent transmission of Las to plants by infected female insect vectors that acquired Las from males during copulation in the current investigation. Although, the overall percentage of sexual transmission of Las from males to females appears low, it could be a highly significant contributing factor to pathogen spread given that thousands of psyllids colonize individual trees. Up to 360 D. citri adults can be captured per sticky trap per tree per week and hundreds to thousands of immature eggs and nymphs can be laid be per tree per week [42].

Collectively our results demonstrate that Las is transmitted from male to female $D$. citri at a low rate during mating. These results suggest that the presumed causal agent of HLB may spread within populations of the vector even in absence of infected host plants. Further investigations are necessary to determine the role of sexual transmission in the epidemiology of HLB disease spread in citrus.

\section{Acknowledgments}

We thank Diann Achor for assistance with transmission electron microscopy. We also thank Michael Flores and Ruben Blanco for help with bioassays and for assistance in performing qPCR. We are grateful to Dr. Sidaram Gowda and Dr. Abigail Walter for providing constructive criticism on a previous version of the manuscript.

\section{Author Contributions}

Conceived and designed the experiments: LLS RSM KPS. Performed the experiments: RSM SLH. Analyzed the data: RSM KPS. Contributed reagents/materials/analysis tools: RSM KPS ST LLS. Wrote the paper: RSM LLS KPS. 


\section{References}

1. Halbert SE, Manjunath KL (2004) Asian citrus psyllids (Sternorrhyncha: Psyllidae) and greening disease of citrus: a literature review and assessment of risk in Florida. Fla Entomol 87: 330-353.

2. Chen J, Civerolo EL, Lee RF, Jones J, Deng X, et al. (2011) "Candidatus Liberibacter sp.", Without Koch's Postulates completed, can the bacterium be considered as the causal agent of citrus Huanglongbing (Yellow Shoot Disease)? Acta Phytopathologica Sinica 41: 113-117.

3. Manjunath KL, Halbert SE, Ramadugu C, Webb S, Lee RF (2008) Detection of Candidatus Liberibacter asiaticus in Diaphorina citri and its importance in the management of citrus huanglongbing in Florida. Phytopathol 98: 387-396.

4. Garnier M, Danel N, Bové JM (1984) The organisms a gram-negative bacterium. In: Garnsey SM, Timmer LW, Dodds JA, eds. Proceedings of the 9th Conference of the International Organization of Citrus Virologists, University of California, Riverside. pp 115-124.

5. Jagoueix SJ, Bové M, Garnier M (1996) PCR detection of the Candidatus Liberibacter species associated with greening disease of citrus. Mol Cell Probes 10: $43-50$.

6. Gotwald TM (2010) Current epidemiological understanding of Citrus Huanglongbing. Annu Rev Phytopathol 48: 119-39.

7. Aubert B (1990) Integrated activities for the control of huanglongbing greening and its vector Diaphorina citri Kuwayama in Asia. In: Aubert B, Tontyaporn S, Buangsuwon D, eds. Proceedings of the Fourth FAO-UNDP International Asia Pacific Conference on Citrus Rehabilitation, 4-10 February 1990, Chiang Mai, Thailand. pp 133-144.

8. Xu CF, Xia YH, Li KB, Ke C (1988) Further study of the transmission of citrus huanglongbing by a psyllid, Diaphorina citri Kuwayama. In: Timmer LW, Garnsey SM, Navarro L, eds. Proceedings of the 10th Conference of the International Organization of Citrus Virologists. Valencia, Spain: University of California, Riverside. pp 243-248.

9. Inoue H, Ohnishi J, Ito T, Tomimura K, Mivata S, et al. (2009) Enhanced proliferation and efficient transmission of Candidatus Liberibacter asiaticus by adult Diaphorina citri after acquisition feeding in the nymphal stage. Ann Appl Biol 155: 29-36.

10. Pelz-Stelinski KS, Brlansky RH, Ebert TA, Rogers ME (2010) Transmission parameters for Candidatus Liberibacter asiaticus by Asian citrus psyllid (Hemiptera: Psyllidae). J Econ Entomol 103: 1531-1541.

11. Knell RJ, Webberley KM (2004) Sexually transmitted diseases of insects: distribution, evolution, ecology and host behavior. Biol Rev Camb Philos Soc 79: 557-581.

12. Ghanim M, Czosnek H (2000) Tomato yellow leaf curl geminivirus (TYLCV-Is) is transmitted among whiteflies (Bemisia tabaci) in a sex-related manner. J Virol 74: $4738-4745$.

13. Ghanim M, Sobol I, Ghanim M, Czosnek H (2007) Horizontal transmission of begomoviruses between Bemisia tabaci biotypes. Arthropod Plant Interact 1: 195-204.

14. Tesh RB (1981) Vertical transmission of Arthropod-borne viruses of vertebrates. In: Vectors of disease agents:interactions with plants, animals and man Mckelvey JJ, Eldridge BF, Maramorosch K, eds. Praeger, New York. pp 122-137.

15. Shroyer DA (1990) Venereal transmission of St. Louis Encephalitis Virus by Culex quinquefasciatus Males (Diptera :Culicidae). J Med Entomol 27: 334-337.

16. Damiani C, Ricci I, Crotti E, Rossi P, Rizzi A, et al. (2008) Paternal transmission of symbiotic bacteria in malaria vectors. Curr Biol 18: R1087-R1088.

17. Moran NA, Dunbar HE (2006) Sexual acquisition of beneficial symbionts in aphids. Proc Natl Acad Sci USA 103: 12803-12806.

18. Hoffmann AA, Turelli M (1997) Cytoplasmic incompatibility in insects. In: O'Neill SL, Hoffmann AA, Werren JH, eds. Influential Passengers: inherited microorganisms and invertebrate reproduction, Oxford University Press, Oxford. pp 42-80.

19. Samakovlis C, Kylsten P, Kimbrell DA, Engstrom A, Hultmark A (1991) The andropin gene and its product, a male-specific antibacterial peptide in Drosophila melanogaster. EMBO J 10: 163-169.

20. Lung O, Kuo L, Wolfner MF (2001) Drosophila males transfer antibacterial proteins from their accessory gland and ejaculatory duct to their mates. J Insect Physiol 47: 617-622.

21. Otti O, Naylor RA, Siva-Jothy MT, Reinhardt K (2009) Bacteriolytic activity in the ejaculate of an insect. Am Nat 174: 292-295.
22. Li W, Hartung JS, Levy L (2006) Quantitative realtime PCR for detection and identification of Candidatus Liberibacter species associated with huanglongbing. J Microbiol Methods 66: 104-115.

23. Thao ML, Moran NA, Abbot P, Brennan EB, Burckhardt DH, et al. (2000) Cospeciation of psyllids and their primary prokaryotic endosymbionts. Appl Environ Microbiol 66: 2898-2905.

24. Wenninger EJ, Hall DG (2007) Daily timing of mating and age at reproductive maturity in Diaphorina citri (Hemiptera: Psyllidae). Fla Entomol 90: 715-722.

25. Damsteegt VD, Postnikova EN, Stone AL, Kuhlmann M, Wilson C, et al. (2010) The relevance of Murraya paniculata and related species as potential hosts and inoculum reservoirs of Candidatus Liberibacter asiaticus, causal agent of Huanglongbing (HLB). Plant Dis 94: 528-533.

26. Onagbola EO, Meyer WL, Boina DR, Stelinski LL (2008) Morphological characterization of the antennal sensilla of the Asian citrus psyllid, Diaphorina citri Kuwayama (Hemiptera: Psyllidae), with reference to their probable functions. Micron 39: 1184-1191.

27. Hung TH, Hung SC, Chen CN, Hsu MS, Su HJ (2004) Detection by PCR of Candidatus Liberibacter asiaticus, the bacterium causing citrus huanglongbing in vector psyllids: application to the study of vector-pathogen relationships. Plant Pathol 53: 96-102.

28. Ammar ED, Shatters RG, Lynch CJ, Hall DG (2011) Detection and relative titer of Candidatus Liberibacter asiaticus in the salivary glands and alimentary canal of Diaphorina citri (Hemiptera: Psyllidae) vector of citrus huanglongbing disease. Ann Entomol Soc Am 104: 526-533.

29. Siva-Jothy MT, Moret Y, Rolff J (2005) Insect immunity: an evolutionary ecology perspective. Adv Insect Physiol 32: 1-48.

30. Wolfner MF (2002) The gifts that keep on giving: physiological functions and evolutionary dynamics of male seminal proteins in Drosophila. Heredity 88: 85-93.

31. Laflèche D, Bové JM (1970a) Structures de type mycoplasma dans les feuilles d'orangers atteints de la maladie du greening. Comptes Rendus de l'Académie des Sciences, Paris 270: 1915-1917.

32. Laflèche D, Bové JM (1970b) Mycoplasmes dans les agrumes atteints de "greening", de "stubborn" ou de maladies similaires. Fruits 25: 455-465.

33. Bové JM (2006) Huanglongbing: A destructive, newly-emerging, century-old disease of citrus. J Plant Pathol 88: 7-37.

34. Sechler A, Schuenzel EL, Cooke P, Donnua S, Thaveechai N, et al. (2009) Cultivation of 'Candidatus Liberibacter asiaticus', 'L. africanus', and 'L. americanus' associated with huanglongbing. Phytopathol 99: 480-486.

35. Hajivand S, Thohirah LA, Kamaruzaman S, Siti NAA (2010) Ultrastructures of Candidatus Liberibacter asiaticus and its damage in huanglongbing (HLB) infected citrus. African J Biotech 9: 5897-5901.

36. Meyer J, Hoy MA (2008) Molecular survey of endosymbionts in Florida populations Diaphorina citri (Hemiptera: Psyllidae) and its parasitoids Tamarixia radiata (Hymenoptera: Eulophidae) and Diaphorencyrtus aligarhensis (Hymenoptera: Encyrtidae). Fla Entomol 91: 294-304.

37. Duan Y, Zhou L, Hall DG, Li W, Doddapaneni H, et al. (2009) Complete genome sequence of citrus huanglongbing bacterium, Candidatus Liberibacter asiaticus obtained through metagenomics. Mol Plant-Microbe Interactions 22: 1011-20.

38. Dossi F, Consoli DF (2010) Desenvolvimento ovariano e infl uência da cópula na maturação dos ovários de Diaphorina citri Kuwayama (Hemiptera: Psyllidae). Neo Entomol 39: 414-419.

39. Raddadi N, Gonella E, Camerota C, Pizzinat A, Tedeschi R, et al. (2011) Candidatus Liberibacter europaeus' sp. nov. that is associated with and transmitted by the psyllid Cacopsylla pyri apparently behaves as an endophyte rather than a pathogen. Environ Microbiol 13: 414-426.

40. Koizumi M, Prommintara M, Ohtsu Y (1996) Wood apple, Limonia acidisima: A new host for the huanglongbing (greening) vector, Diaphorina citri. In: da Graca JV, Moreno P, Yokomi RK, eds. Proceedings of $13^{\text {th }}$ Conference of the International Organization of Citrus Virologists (IOBC), University of California, Riverside. pp 271-275.

41. Hall DG (2008) Biology, history and world status of Diaphorina citri. Taller Internacional Sobre Huanglongbing de los Citricos. Hermosillo, Sonora. Mexico I: $1-11$.

42. Hall DG (2009) An assessment of yellow sticky card traps as indicators of the abundance of adult Diaphorina citri (Hemiptera: Psyllidae) in citrus. J Econ Entomol 102: 446-452. 